\title{
Optimization of High-Speed Train Control Strategy for Traction Energy Saving Using an Improved Genetic Algorithm
}

\author{
Ruidan Su, ${ }^{1}$ Qianrong Gu, ${ }^{2}$ and Tao Wen ${ }^{1}$ \\ ${ }^{1}$ College of Information Science and Engineering, Northeastern University, Shenyang 110004, China \\ ${ }^{2}$ Service Science Research Center, Shanghai Advanced Research Institute, Chinese Academy of Sciences, Shanghai 201203, China \\ Correspondence should be addressed to Ruidan Su; suruidan@hotmail.com
}

Received 27 March 2014; Accepted 9 April 2014; Published 4 May 2014

Academic Editor: Young-Sik Jeong

Copyright (c) 2014 Ruidan Su et al. This is an open access article distributed under the Creative Commons Attribution License, which permits unrestricted use, distribution, and reproduction in any medium, provided the original work is properly cited.

\begin{abstract}
A parallel multipopulation genetic algorithm (PMPGA) is proposed to optimize the train control strategy, which reduces the energy consumption at a specified running time. The paper considered not only energy consumption, but also running time, security, and riding comfort. Also an actual railway line (Beijing-Shanghai High-Speed Railway) parameter including the slop, tunnel, and curve was applied for simulation. Train traction property and braking property was explored detailed to ensure the accuracy of running. The PMPGA was also compared with the standard genetic algorithm (SGA); the influence of the fitness function representation on the search results was also explored. By running a series of simulations, energy savings were found, both qualitatively and quantitatively, which were affected by applying cursing and coasting running status. The paper compared the PMPGA with the multiobjective fuzzy optimization algorithm and differential evolution based algorithm and showed that PMPGA has achieved better result. The method can be widely applied to related high-speed train.
\end{abstract}

\section{Introduction}

Since October 1964 the world's first high-speed railway, Japan Tokaido Shinkansen, was born; high-speed railways started the rapid development. Today, most European countries, Russia, Japan, and China have constructed their complex high-speed railways networks. Although the railway was considered the most efficient way of travel, compared to aircraft and auto vehicle, it still consumes large amount of energy [1] in everyday running. Researches showed that it still has large possibility to make the train run more efficiently [24]. The reduction of energy consumption is also seen as one of the key objectives for the development of sustainable mobility by use of high-speed train. Research will lead to a decrease of huge energy consumption in everyday running of high-speed trains. Many scholars have been engaged in it.

Yang et al. [5] from Tongji University proposed a new energy conservation track profile based on trigonometric function method in urban mass transit. Simulation results showed that it was effective in comparison with actual track profile. Bocharnikov et al. [6] applied a method for saving energy consumption during a single-train journey by trading off reductions in energy against increases in running time; in Bocharnikov's research, energy savings were found to be affected by acceleration and braking rates and by running a series of simulations in parallel with a genetic algorithm search method. Chen et al. [7] employed genetic algorithms to optimize train scheduling. The result showed that the method can significantly reduce the maximum traction power. Although these methods and algorithms were effective, they can only be applied in mass rapid transit (MRT) and light rapid transit (LRT) systems. Usually, in MRT, distance between two stations was short and the top running speed was about $80-100 \mathrm{~km} / \mathrm{h}$. In this case, a train generally must decelerate in preparation for reaching the next station before it reaches the speed limit. In Milroy's doctoral dissertation [8], Aspects of Automatic Train Control, it was proved that for short distance train control represents three different motion regimes, including acceleration, coasting, and braking. But later, in 1984, Howlett [9] proved that in long distance train running, cruising was significant in minimizing energy consumption. Due to the difference between MRT, LRT, and 
high-speed trains, these methods cannot be applied in highspeed trains for energy optimization.

For high-speed trains, energy saving and trains control optimization were also studied by scholars. Kawakami [10] from Central Japan Railway Company presents a dynamic power saving strategy for Shinkansen traffic control; the author made conclusion that predictive simulations in every layer and target shooting operation of trains are the basis for energy control. With consideration of track gradient and speed limits, Cheng [11] summarized train control problems with two different models, traction mechanical energy model (TMEM) and traction energy model (TEM), in a long-haul train. Hwang [12] presented an approach to identify a fuzzy control model for determining an economic running pattern for a high-speed railway through an optimal compromise between trip time and energy consumption.

In this paper, taking the Beijing-Shanghai High-Speed Railway as a case, an improved PMPGA was applied to find a perfect running with a specified running. In this research, security, stop precision, and riding comfort were considered and also the railway line parameter includes the slop, tunnel, and curve. The result demonstrates that the PMPGA improved algorithm was better with the SGA and it has achieved conspicuous energy reduction.

\section{Train Traction Module}

2.1. Train Traction Property. Traction property curve is an important curve demonstrating the relationship between train traction effort and speed. It was the most significant work when a train was designed. Figure 1 shows the schematic diagram of traction property curve calculation.

In Figure 1, there are three curves; the top one is adhesionlimited braking force $F_{\max }=f(v)$, the middle one is traction effort property $F=f(v)$, and the bottom one, denoted as $\mathrm{W}$, is the sum of resistances (e.g., bearing, rolling, air, and grade resistance) $W=f(v)$. Note that point $\mathrm{A}$, the cross of $F_{\max }=$ $f(v)$ and $W=f(v)$, correspond $v_{a}$, is greater than the $v_{\max }$. Now, according to the curve, traction effort property $F=f(v)$ could be generated as

$$
\begin{aligned}
& \frac{\left(F_{v}-F_{v 0}\right)}{v}=\frac{\left(F_{v^{\prime}}-F_{v 0}\right)}{v^{\prime}} \quad 0 \leq v \leq v^{\prime} \\
& F_{v} * v=F_{\max } * V_{\max } \quad v^{\prime} \leq v \leq v_{\max }
\end{aligned}
$$

In the above formula, $F_{v}$ represents the traction force when the speed is $v \cdot v^{\prime}$ is the speed on the intersection point of constant moment segment and constant power segment. $F_{\max }$ represents traction force limitation.

2.2. Train Resistance. To ensure that the TE was able to drive the train with a speed, the total resistances, in this paper, defined as $W$, must be known. Total resistances include basic resistance $W_{0}$ (axle friction resistance, track resistance, rolling resistance, journal resistance, air force resistance, and vibration resistance) and extra resistance $W_{j} . W_{j}$ includes grade resistance $\left(W_{i}\right)$, curve resistance $\left(W_{r}\right)$, and tunnel resistance $\left(W_{s}\right)$.

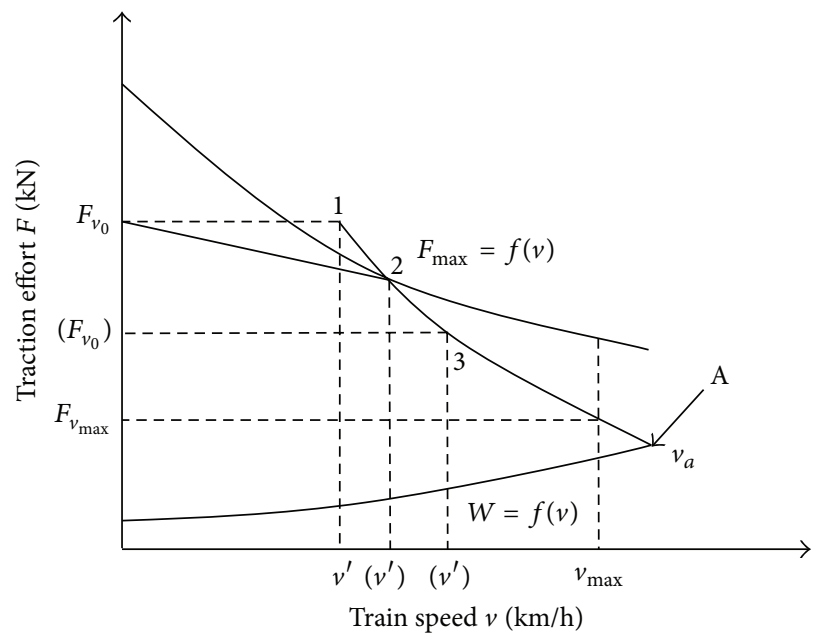

FIgURE 1: Diagram of traction property curve calculation.

It [13] was found that speed was the main factor which effects the basic resistance, and basis resistance can be expressed by a quadratic equation formulated as follows:

$$
\omega_{0}=a+b v+c \cdot v^{2}
$$

where the coefficients $a, b$, and $c$ are dependent on axle load, number of axles, cross-section of the train, and shape of the train.

According to [14], considering the train as a multiparticle object, we can have the $w_{j}(x)$ as the following function:

$$
w_{j}(x)=\frac{1}{L}\left[\sum i_{i} * l_{i}+600 \sum \frac{l_{r i}}{R}+\sum\left(w_{s} * l_{s}\right)\right],
$$

where $L$ is the length of the train and $i_{i}$ and $l_{i}$ represent the gradient and grade length. $R, l_{r i}$ are the curve radius and length. $w_{s i}, l_{s i}$ are the tunnel resistance and length.

Then, the motion equation and the $a, v_{i}$, and $S_{i}$ were formulated as below:

$$
\begin{gathered}
a=\frac{d v}{d t}=\frac{F-B-\left(\omega_{i}+\omega_{r}+\omega_{s}+\omega_{0}\right)}{M(1+\gamma)} \\
V_{i}=a \Delta t+V_{i-1} \\
S_{i}=\frac{V_{i}+V_{i-1}}{2} \Delta t+S_{i-1},
\end{gathered}
$$

where $V_{i}$ was the speed of current moment, $v_{i-1}$ was the speed of last moment, $a$ was the acceleration of current moment, $s_{i}$ was the distance of current moment from the first station, and $s_{i-1}$ was the distance of the last moment from the first station.

\section{Traction Energy Module (TEM)}

In order to achieve minimal energy consumption, generally, train control for running between stations, including acceleration, cruising, coasting, and braking, should be applied at appropriate time. Golovitcher [15] and Khmelnitsky [16] analyzed the train movement process with nonlinear constrained 


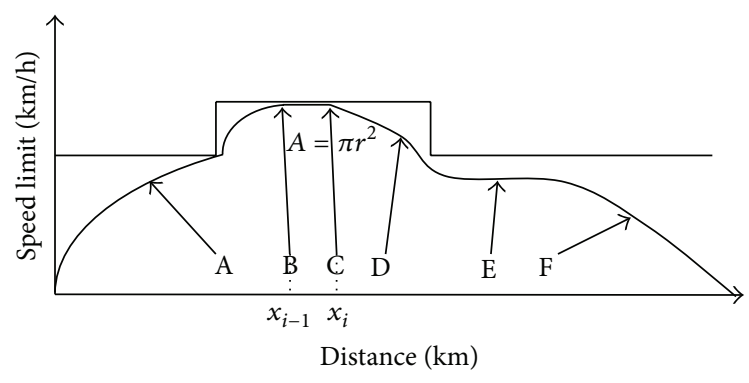

Figure 2: Diagram of different running status during one journey.

differential equations and concluded that a maximum economic train running strategy should contain four statuses, maximum traction, cursing, coasting, and maximum braking. For analyzing station-to-station travel time and distance profile, it is essential to comprehend the description of the motion statuses and their mathematical expressions. In maximum traction, power is used to overcome gravity (if climbing) and the dynamic resistance so as to accelerate. When cruising, power is used to overcome the resistance to maintain the train at the constant speed; at this time, the acceleration is zero. When coasting, the running train only suffers from the force of resistance. Applying coasting when the train runs between stations as much as possible is considered to be the most effective energy consumption way. When braking, with regeneration technology fitted, energy can be produced using the motor as a generator.

A train's journey may have variables coast intervals (Figure 2) to achieve an optimal solution. Figure 2 shows a train's status and changing point during a running between two stations. In the figure, the points mean the following: A: traction; B: cursing start point; C: coasting start point; D: coasting; E: cursing; F: braking.

Now, the aim is to find an optimal control strategy for minimal energy consumption in a round trip between two stations. This problem can be seen as a double optimization problem.

Traction energy module can be described as follows.

Make $X$ the distance between two stations, and travel time was fixed $T ;[0, T]$ can be divided as

$$
0=t_{0} \leq t_{1} \leq t_{2} \cdots \leq t_{n} \leq t_{n+1}=t,
$$

where $t_{0}$ is the initial time and $t_{n+1}$ is the final time; in the time space $\left[t_{k}-t_{k+1}\right]$ train travel distance is $\left[x_{k}-x_{k+1}\right]$ and in $[0, x]$

$$
0=x_{0} \leq x_{1} \leq x_{2} \leq \cdots \leq x_{n} \leq x_{n+1}=x .
$$

Total energy consumed by the train can be defined as follows:

$$
\begin{gathered}
\min E=\int_{x_{0}}^{x_{f}} u_{f}(x) f(v) d x \\
\text { s.t. }\left\{\begin{array}{c}
\frac{d t}{d x}=\frac{1}{v} \\
v \frac{d v}{d x}=\frac{u_{f}(x) f(x)-u_{b}(x) b(v)}{M g}-w_{0}(v)-w_{j}(x)
\end{array}\right.
\end{gathered}
$$

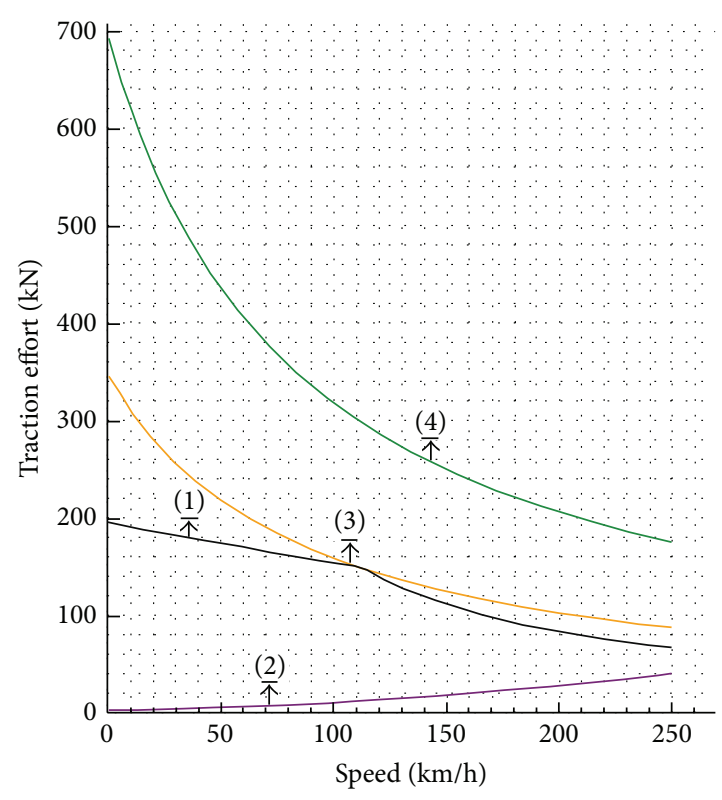

Curve 1: train traction property

Curve 2: basic resistance

Curve 3: adhesion-limited braking force (wet)

Curve 4: adhesion-limited braking force (dry)

FIGURE 3: Train traction property and adhesion-limited braking force.

$$
\begin{gathered}
t\left(x_{0}\right)=0, t\left(x_{f}\right)=T, v\left(x_{0}\right)=0, v\left(x_{f}\right)=0 \\
v \leq V(x), u_{f} \in[0,1], u_{b} \in[0,1]
\end{gathered}
$$

where $E$ is the energy consumption and $T$ is a fixed time when the train travels between two stations. $t\left(x_{0}\right)$ is start time, $t\left(x_{f}\right)$ is arrival time, and $v\left(x_{0}\right)$ and $v\left(x_{f}\right)$ represent the start speed and final speed; it was obvious that $v\left(x_{0}\right)$ and $v\left(x_{f}\right)$ are equal to $0 . u_{f}$ and $u_{b}$ were coefficient of traction power and braking.

Then the train control strategy set was $S=\{s i\}=$ $\{\operatorname{traction}(\mathrm{T}), \operatorname{cursing}(\mathrm{CR}), \operatorname{coasting}(\mathrm{C}), \operatorname{Braking}(\mathrm{B})\}=$ $\{\mathrm{T}, \mathrm{CR}, \mathrm{C}, \mathrm{B}\}$.

Finally, the train control matrix was defined as

$$
C=\left[c_{0}, c_{1}, c_{2}, \ldots, c_{i}, \ldots, c_{n-1}, c_{n}\right],
$$

where $c_{i}=\left[x_{i}, s_{i}\right], x_{i}$ is the position, and $s_{i}$ is the control strategy start at the position $x_{i}$. From Figure 2, we can see that $s_{i} \in \mathrm{S}$. $x_{0}=0$ and $x_{n}$ can be easily calculated by the last braking process.

\section{Minimize the Energy Consumption with Parallel Multipopulation Genetic Algorithm}

The genetic algorithm (GA) $[9,10]$ is a method for solving both constrained and unconstrained optimization problems based on natural selection, the process that drives biological evolution. The genetic algorithm repeatedly modifies a population of individual solutions [17]. At each step, the GA 
TABLE 1: Experiment of PMPGA with different subpopulation group and gene length.

\begin{tabular}{lccccccc}
\hline Experiment & $N_{\mathrm{sp}}$ & Gene length & Group size & $P_{c}$ & Generation & $P_{m}$ & $P_{v}$ \\
\hline E1 & 3 & 50 & 100 & 0.7 & 300 & 0.068 \\
E2 & 3 & 100 & 100 & 0.7 & 300 & 0.2 \\
E3 & 6 & 50 & 100 & 0.7 & 150 & 0.068 & 0.068 \\
\hline
\end{tabular}

selects individuals at random from the current population to be parents and uses them to produce the children for the next generation. Over successive generations, however, as we all know, the standard GA has the premature convergence phenomenon and slow searching process. In our research, we apply PMPGA, which is a simulation of gene isolation and gene migration in biological evolution process where all populations are divided into many subpopulations with different control. Because the subpopulations have different gene patterns and their genetic processes are independent, the global optimum and the fully search are guaranteed by the difference in evolutionary direction. The optimal individual is quoted by other subpopulations through migration operator.

Finally, considering the optimal object and the constraint conditions, the PMPGA compute process can be described as below.

4.1. Chromosome. Take the sequence of train control strategy, which contains the sequence of train operating conditions and the corresponding sequence of conversion locations for the operation section, as a chromosome. The function is

$$
C=\left[\left(x_{0}, s_{0}\right)\left(x_{1}, s_{1}\right) \cdots\left(x_{i}, s_{i}\right) \cdots\left(x_{l}, s_{l}\right)\right],
$$

where $c_{i}=\left[x_{i}, s_{i}\right], x_{i}$ is the position, and $s_{i}$ is the control strategy start at the position $x_{i} . s_{i}$ were discrete variables which contain four control strategies [T, CR, C, B]; each control strategy corresponds to one energy consumption formula. $x_{i}$ uses the real number encoding. $l$ is the length of chromosome and it is also variable.

4.2. Initial Population. Population is constructed using chromosomes; each chromosome represents a single solution point in the problem space. In our research, donate individual matric $U(U \in C)$ was randomly created with different gene length. Gene length means possible times of traction strategy during a running. Consider the distance between two stations. We assign the maximum gene length as $G L_{\max }$. Each $U^{\prime}$ was a control matrix and all created Us compose $N$ subpopulation group; each subpopulation group is denoted as $P=$ $\left\{p_{1}, p_{2}, p_{3}, \ldots, p_{k}\right\}$, and $k$ is the number of populations in a subpopulation group. In our research $N_{\mathrm{sp}}$ assigned as number of subpopulation groups will be computed in parallel.

4.3. Fitness Function. Applying the individual which means the control matrix to the energy calculated formula, we can get the object value. The fitness evaluation is based on the minimization of the energy consumption, which is defined as

$$
\operatorname{Fit}(x)=\frac{1}{C_{\max }+o b j+C} \text {. }
$$

Considering the fastest running strategy, the maximum energy consumption is about $4000 \mathrm{kwh}$; we make coefficient $C_{\max }$ as 4000 and $c$ was 0.1 .

4.4. Standard of Convergence. The convergence criterion is whether the maximum evolutionary generation is reached or the best individual remains unchanged among several generations. If the algorithm is not convergent, then continue to the next operations; otherwise, searching process ends.

Selection operation: Roulette wheel selection first calculates each individual $x_{i}^{\prime}$ corresponding proportion of its fitness value to the total fitness value of the whole population, labeled as $p_{i}$, by

$$
p_{i}=\frac{\operatorname{Fit}\left(x_{i}\right)}{\sum_{j=1}^{N} \operatorname{Fit}\left(x_{j}\right)}
$$

where $i=1,2, \ldots, N$ and $N$ is the size of population. Then the operator repeats $N$ times of selecting an individual from the current population to generate the new population. In each time, $a$ random real number $q$ uniformly scattered in the range $(0,1)$ is generated, and the individual $x_{k}$ where $k$ satisfies (20) is selected:

$$
k=\min \left\{j \mid \sum_{i=1}^{j-1} p_{i} \leq q, j=1,2, \ldots, N\right\} .
$$

It is obvious that, in the roulette wheel selection, the fitter individuals have a greater chance of survival than the greater ones.

Crossover. Uniform crossover operator: the crossover operator works as follows. After the two "parents" are drawn, each corresponding pair of coordinates exchanges its values independently, with the same probability $0<r<1$, as follows:

$$
\begin{aligned}
& X_{1}^{t+1}=r X_{1}^{t}+(1-r) X_{2}^{t} \\
& X_{2}^{t+1}=r X_{2}^{t}+(1-r) X_{1}^{t} .
\end{aligned}
$$

In formula (13) $X_{1}^{t}, X_{2}^{t}$ represent the gene of parents and $X_{1}^{t+1}, X_{2}^{t+1}$ represent the next generation.

Mutation Operator. Using random number generator to generate a number between 0 and 1 , if it is less than the probability of mutation $p_{m}$, chromosomes do mutation. Several mutation positions are rolled randomly.

In order to find the best solution, we define different gene length and different number of subpopulation groups for confrontation. By SGA, the population size is 100, gene 


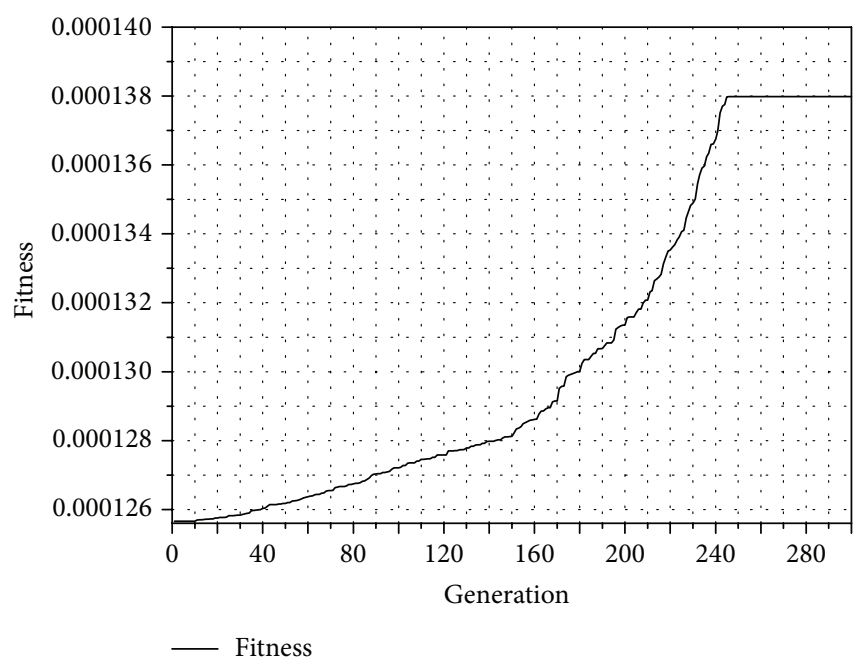

(a)

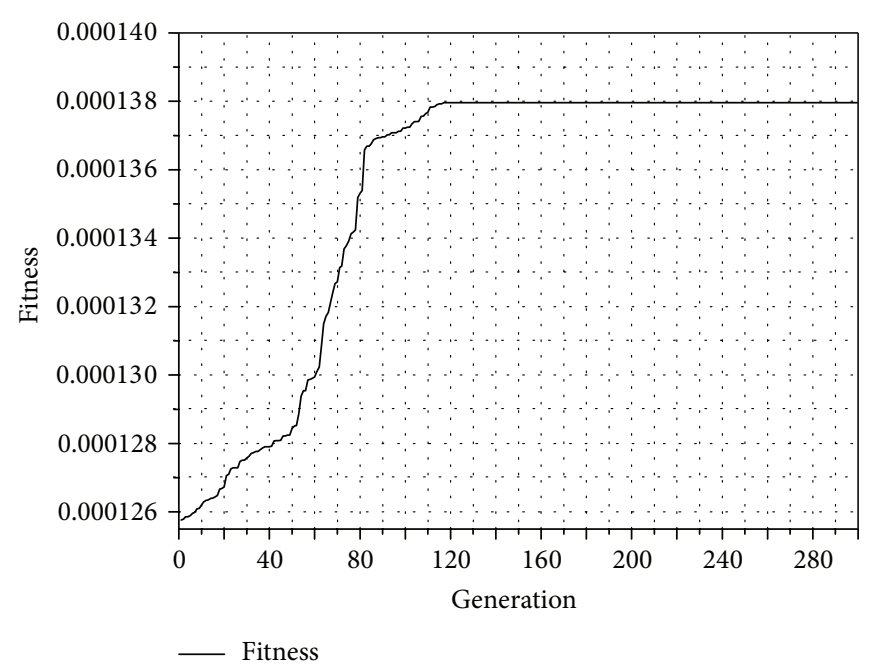

(b)

FIGURE 4: Evolutionary curve of standard GA (left) and PMPGA E1 (right).

TABLE 2: Basic train information.

\begin{tabular}{lc}
\hline Motor car/trailer/number of cars & $14 / 2 / 16$ \\
Number of axles & 64 \\
Train weight & $895.6(\mathrm{t})$ \\
Outpower $(\mathrm{kw})$ & $615 * 16$ \\
Voltage rating $(\mathrm{v})$ & 3000 \\
Current rating $(\mathrm{A})$ & 230 \\
Highest running speed $(\mathrm{km} / \mathrm{h})$ & 380 \\
Cursing speed $(\mathrm{km} / \mathrm{h})$ & 350 \\
\hline
\end{tabular}

length is 50, the maximum evolutionary generation is 300 , and $\mathrm{Pc}=0.7, \mathrm{Pm}=0.068$, and $\mathrm{Pv}=0.2$. The specified running time is 20 mins. The adjustment coefficient $\mathrm{A}$ of running performance index function is 3.6. The update time interval is $1 \mathrm{~s}$ for multiparticle train simulator (see Table 1).

By PMPGA, we try 3 groups of experiments as below, and the update time interval is $1 \mathrm{~s}$ for multiparticle train simulator.

\section{Case Study and Simulation}

In this project, we use $c \#$ to develop a simulation environment. Then the improved train control strategy can be verified and compared with the previous one. The trains run in the Beijing-Shanghai High-Speed Railway from Beijing to Langfang; the line length is $1305.121 \mathrm{~km}$ and the distance between Beijing and Langfang is $59.5 \mathrm{~km}$. Reality line parameters including grade, tunnel, curve, and speed restriction are all considered in the simulation.

Train traction property, basic train information, and reality line parameters were showed in Figure 3, Table 2, and Table 3.

From the simulation result, Figure 4 shows that, with standard GA, the maximum fitness rises much faster after the 140 th generation and even faster at the 220th generation; after about the 240th generation, the fitness reaches the maximum value and becomes stable after that. Compared with the E1, the maximum fitness rises sharply at the 75th generation and becomes stable from the 120th generation. The result shows that the parallel multipopulation GA has the speed of convergence and the precision is considerably improved; also it avoids the premature convergence phenomenon of single-population evolutionary algorithm and maintains the evolutionary stability of the best individuals.

For experiment E1 (Figure 4, right) and E2 (Figure 5, left), we can see that the gene length was extended to 100 which does not cause any improvement. Both curves reach the maximum value and become stable at about the 120th generation. From the result of E1, the gene length 50 is enough for the control strategy between two stations.

For experiment E3, when $N_{\text {sp }}$ was extended from 3 to 6, gene length was set as 50 and generation was set as 150 . The speed of convergence was improved. At about the 85th generation, the curves become stable and reach the maximum value.

When applying the control strategy to the simulation system, we got the following result.

From Figure 6 we can see that the running strategy was applied to save energy consumption, and cursing and coasting strategy were also applied in appropriate time. Running results were compared in Table 4.

We can see that when running time from Beijing to Langfang was $16^{\prime} 32^{\prime \prime}$ when applying the fastest strategy, energy consumption is $3957.7 \mathrm{kwh}$. When running time was set extended to $20^{\prime} 00^{\prime \prime}$, energy consumption was reduced to about $3252.4 \mathrm{kwh}$ and $3247.2 \mathrm{kwh}$, which save $17.82 \%$ and $17.95 \%$ compared with the fastest running time.

In order to verify the efficiency of the PMPGA, we compared it with another optimal algorithm; one is from YanXH who proposed an algorithm based on differential evolution [18] and the other one is from WangDC who proposed a multiobjective fuzzy optimization [19]. We set up module, apply the algorithm at the same train and same 


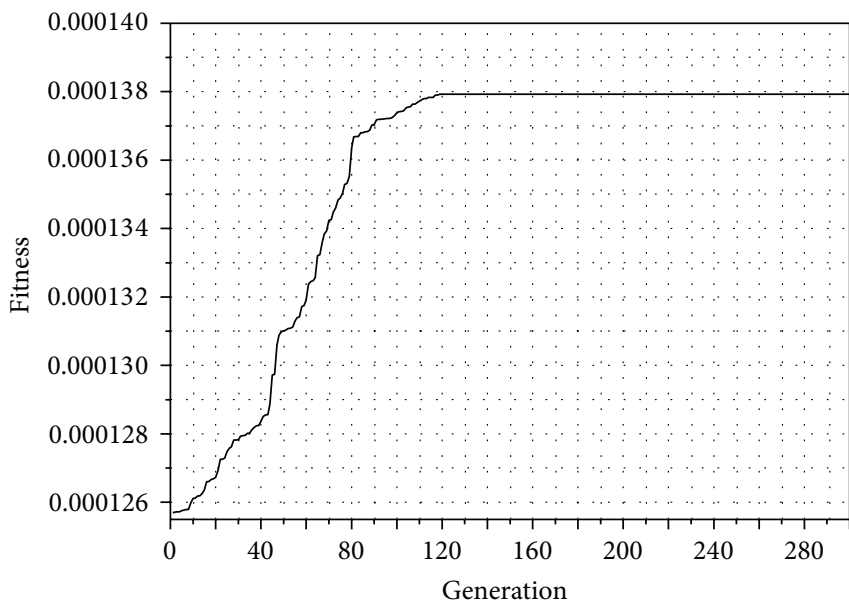

— Fitness

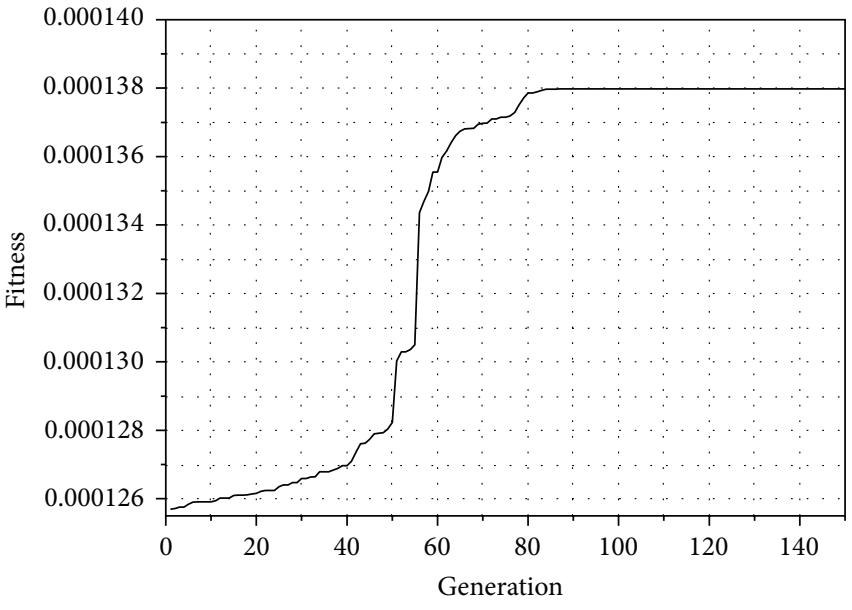

— Fitness

(a)

(b)

FIGURE 5: Evolutionary curve of E2 (left) and E3 (right).

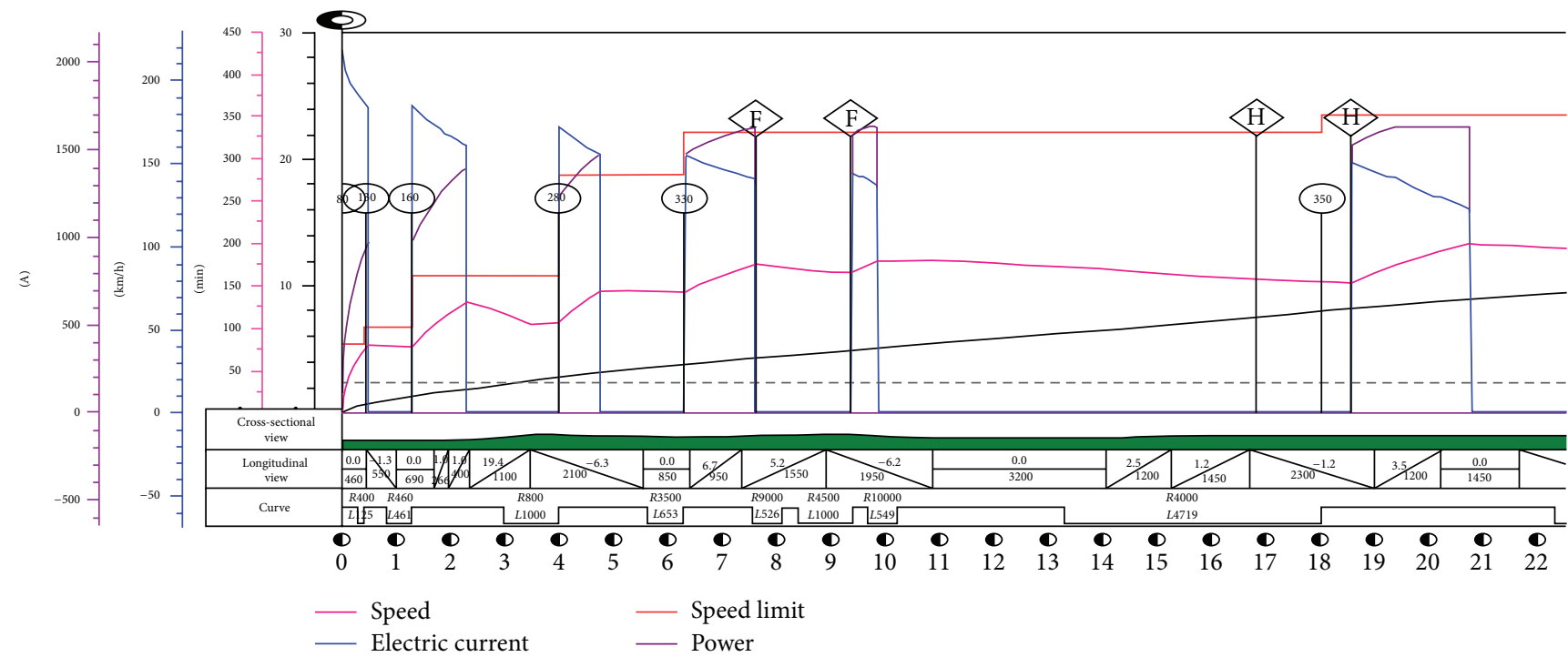

FIGURE 6: Result of normal specified time running strategy.

TABLE 3: Railways line parameters and units.

\begin{tabular}{|c|c|c|c|c|c|c|c|c|c|c|c|}
\hline Distance & Gradient & Altitude & $\begin{array}{l}\text { Slope } \\
\text { length }\end{array}$ & $\begin{array}{c}\text { Curve } \\
\text { position }\end{array}$ & $\begin{array}{l}\text { Curve } \\
\text { radius }\end{array}$ & $\begin{array}{l}\text { Curve } \\
\text { length }\end{array}$ & Station & $\begin{array}{c}\text { Speed } \\
\text { limit }\end{array}$ & $\begin{array}{c}\text { Tunnel } \\
\text { position }\end{array}$ & $\begin{array}{c}\text { Bridge } \\
\text { position }\end{array}$ & Others \\
\hline $\mathrm{km}$ & $\%$ & $\mathrm{~m}$ & $\mathrm{~m}$ & $\mathrm{~km}$ & $\mathrm{~m}$ & $\mathrm{~m}$ & $\mathrm{~km}$ & $\mathrm{~km} / \mathrm{h}$ & $\mathrm{km}$ & $\mathrm{km}$ & - \\
\hline
\end{tabular}

TABLE 4: Comparison of running results.

\begin{tabular}{lccccc}
\hline Rail line & Section length & Running strategy & Time set & Actual running time & Energy consumption \\
\hline Beijing-Langfang & $59.5 \mathrm{~km}$ & Fastest & - & $16 \mathrm{~min} 32 \mathrm{~s}$ & $3957.7 \mathrm{kwh}$ \\
Beijing-Langfang with SGA & $59.5 \mathrm{~km}$ & Specified time & $20 \mathrm{~min} 00 \mathrm{~s}$ & $19 \mathrm{~min} 59 \mathrm{~s}$ & $3252.4 \mathrm{kwh}$ \\
Beijing-Langfang with PMPGA & $59.5 \mathrm{~km}$ & Specified time with GA & $20 \mathrm{~min} \mathrm{00 \textrm {s }}$ & $20 \mathrm{~min} 00 \mathrm{~s}$ & $3247.2 \mathrm{kwh}$ \\
\hline
\end{tabular}


TABLE 5: Experiment confrontation with other algorithms.

\begin{tabular}{|c|c|c|c|c|c|}
\hline Experiment & Section length & Running strategy & Time set & Actual running time & Energy consumption \\
\hline $\begin{array}{l}\text { Beijing-Langfang with } \\
\text { PMPGA }\end{array}$ & $59.5 \mathrm{~km}$ & Specified time with GA & $20 \min 00 \mathrm{~s}$ & $20 \min 00 \mathrm{~s}$ & $3247.2 \mathrm{kwh}$ \\
\hline $\begin{array}{l}\text { Beijing-Langfang } \\
\text { E5 }\end{array}$ & $59.5 \mathrm{~km}$ & Differential evolution & $20 \min 00 \mathrm{~s}$ & $20 \min 00 \mathrm{~s}$ & $3362.9 \mathrm{kwh}$ \\
\hline $\begin{array}{l}\text { Beijing-Langfang } \\
\text { E6 }\end{array}$ & $59.5 \mathrm{~km}$ & Fuzzy optimization & $20 \mathrm{~min} 00 \mathrm{~s}$ & $19 \min 59 \mathrm{~s}$ & $3402.1 \mathrm{kwh}$ \\
\hline
\end{tabular}

railway lines, and get the following results. In Table 5, we define Yan's experiment as E5 and Wang's as E6. The result shows that, with Yan's algorithm, the train was run with a better accuracy in time and E6 is worse. But E5 and E6's experiments show that the energy consumption was about $3.56 \%$ and $4.77 \%$ more than the PMPGA result. It is proved that the PMPGA algorithm is better with the fuzzy control optimization and algorithm based on differential evolution.

\section{Conclusion}

When a train running schedule is fixed, security, stop precision, and riding comfort must be satisfied. We can save energy consumption by optimizing the control strategy. In this paper, a SGA and PMPGA were applied to find a perfect running based on a specified time. By taking the Beijing-Shanghai High-Speed Railway (Beijing-Langfang section) as a case, the result demonstrates that the SGA and PMPGA were able to reduce energy consumption, but the improved PMPGA has higher speed to convergence and has achieved conspicuous energy reduction; also, PMPGA has achieved better result compared with the multiobjective fuzzy optimization algorithm and differential evolution based algorithm.

\section{Conflict of Interests}

The authors declare that there is no conflict of interests regarding the publication of this paper.

\section{References}

[1] V. Prakash Bhardwaj and Nitin, "On the minimization of crosstalk conflicts in a destination based modified omega network," Journal of Information Processing Systems, vol. 9, no. 2, pp. 301-314, 2013.

[2] J. Hui Chong, C. Kyun Ng, N. Kamariah Noordin, and B. Mohd Ali, "Dynamic transmit antenna shuffling scheme for MIMO wireless communication systems," Journal of Convergence, vol. 4, no. 1, 2013.

[3] S. Masoumi, R. Tabatabaei, M.-R. Feizi-Derakhshi, and K. Tabatabaei, "A new parallel algorithm for frequent pattern mining," Journal of Computational Intelligence and Electronic Systems, vol. 2, no. 1, pp. 55-59, 2013.

[4] H. Kumar Gupta, P. K. Singhal, G. Sharma, and D. Patidar, "Rectenna system design in L-band (1-2 GHz) 1.3 GHz for wireless power transmission," Journal of Computational Intelligence and Electronic Systems, vol. 1, no. 2, pp. 149-153, 2012.
[5] L. Yang, Y. Hu, and L. Sun, "Energy-saving track profile of urban mass transit," Journal of Tongji University, vol. 40, no. 2, pp. 235240, 2012.

[6] Y. V. Bocharnikov, A. M. Tobias, C. Roberts, S. Hillmansen, and C. J. Goodman, "Optimal driving strategy for traction energy saving on DC suburban railways," IET Electric Power Applications, vol. 1, no. 5, pp. 675-682, 2007.

[7] J.-F. Chen, R.-L. Lin, and Y.-C. Liu, "Optimization of an MRT train schedule: reducing maximum traction power by using genetic algorithms," IEEE Transactions on Power Systems, vol. 20, no. 3, pp. 1366-1372, 2005.

[8] I. P. Milroy, Aspects of automatic train control [Ph.D. thesis], Loughborough University, 1980.

[9] P. G. Howlett, "Existence of an optimal strategy for the control of a train," School of Mathematics Report \#3, University of South Australida, 1988.

[10] T. Kawakami, "Integration of heterogeneous systems," in Proceedings of the Fourth International Symposium on Autonomous Decentralized Systems, pp. 316-322, 1993.

[11] J.-X. Cheng, "Modeling the energy-saving train control problems with a long-haul train," Journal of System Simulation, vol. 11, no. 4, 1999.

[12] H. S. Hwang, "Control strategy for optimal compromise between trip time and energy consumption in a high-speed railway," IEEE Transactions on Systems, Man, and Cybernetics A: Systems and Humans, vol. 28, no. 6, pp. 791-802, 1998.

[13] T. Songbai, "Study on the running resistance of Quasi-high speed passenger trains," Science of China Railways, vol. 18, no. $1,1997$.

[14] Z. Zhongyang and S. Zhongyang, "Analysis of additional resistance calculation considering the length of the train and discuss of the curve additional resistance clause in the Traction Regulations," Railway Locomotive \& Car, vol. 2, 2000.

[15] I. Golovitcher, "An analytical method for optimum train control computation," Izvestiya Vuzov Seriya Electrome Chanica, no. 3, pp. 59-66, 1986.

[16] E. Khmelnitsky, "On an optimal control problem of train operation," Institute of Electrical and Electronics Engineers. Transactions on Automatic Control, vol. 45, no. 7, pp. 1257-1266, 2000 .

[17] B. Singh and D. Krishan Lobiyal, "A novel energy-aware cluster head selection based on particle swarm optimization for wireless sensor networks," Human-Centric Computing and Information Sciences, vol. 2, article 13, 2012.

[18] X. H. Yan, B. G. Cai, and B. Ning, "Research on multi-objective high-speed train operation optimization based on differential evolution," Journal of the China Railway Society, vol. 35, no. 9, 2013.

[19] D. C. Wang, K. P. Li, and X. Li, "Multi-objective energy-saving train scheduling model based on fuzzy optimization algorithm," Science Technology and Engineering, vol. 12, no. 12, 2012. 


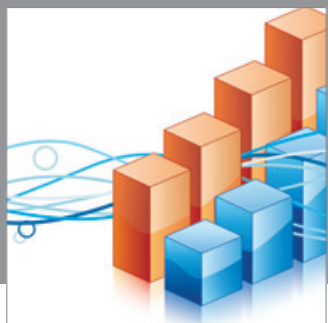

Advances in

Operations Research

mansans

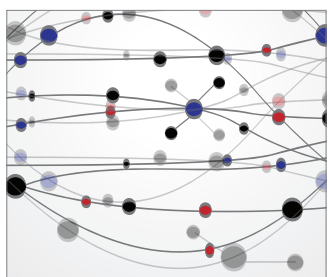

The Scientific World Journal
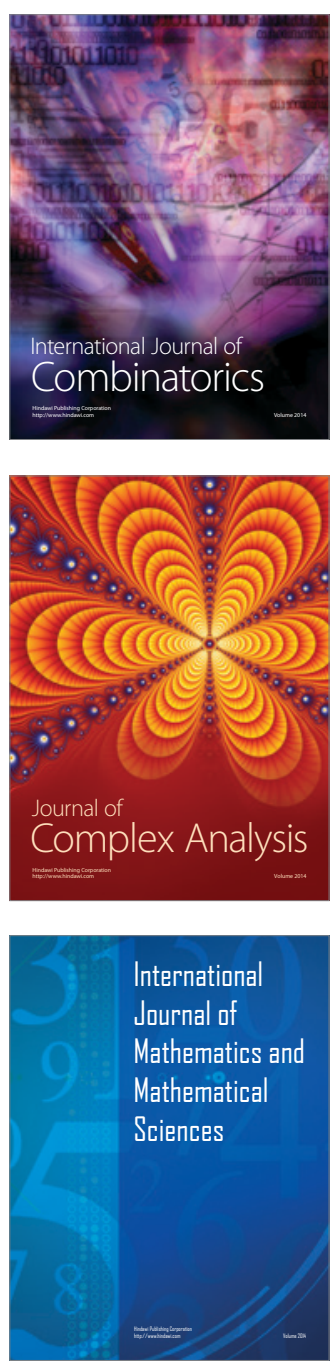
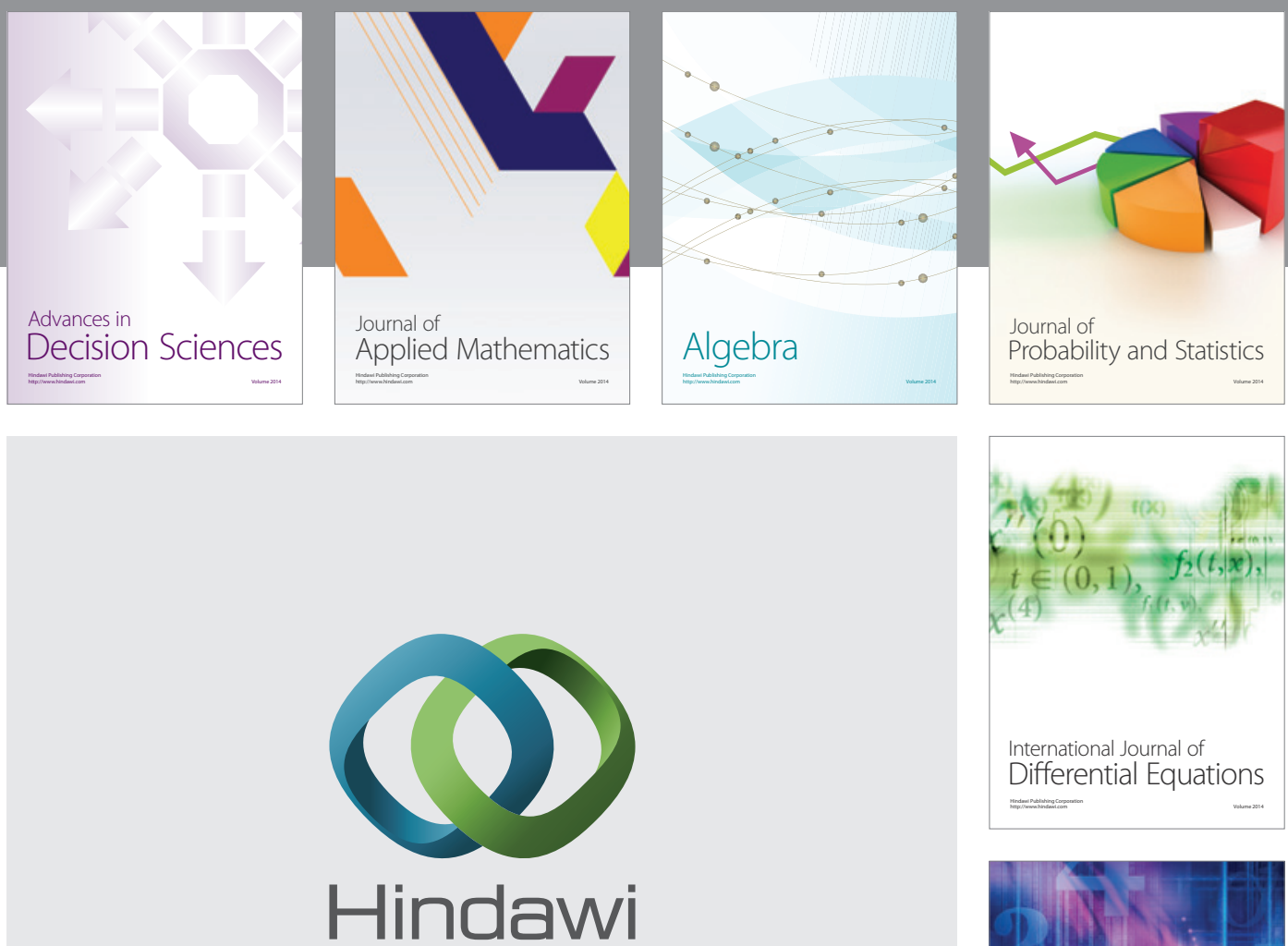

Submit your manuscripts at http://www.hindawi.com
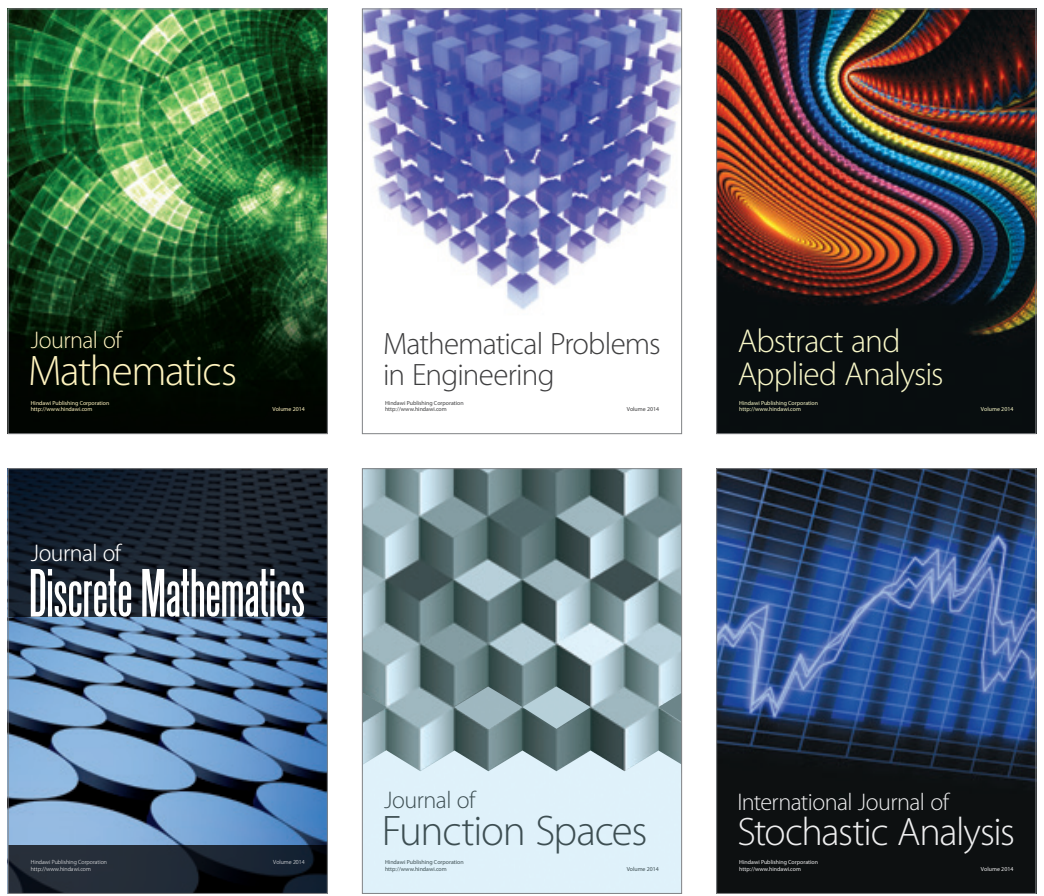

Journal of

Function Spaces

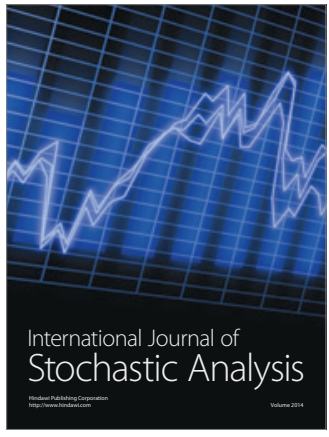

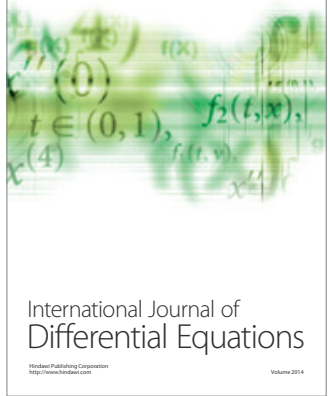
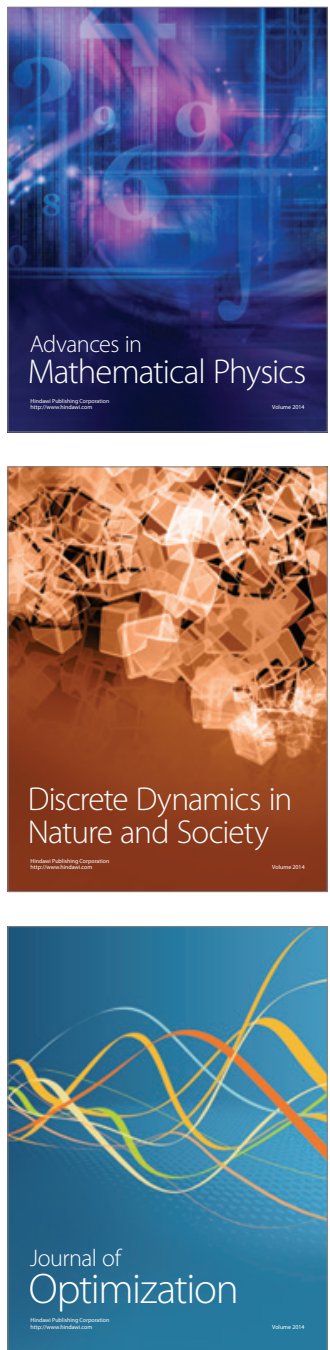